\title{
Anemia risk in relation to lead exposure in lead-related manufacturing
}

\author{
Nan-Hung Hsieh? ${ }^{1}$, Shun-Hui Chung ${ }^{2}$, Szu-Chieh Chen ${ }^{3,4}$, Wei-Yu Chen ${ }^{5}$, Yi-Hsien Cheng ${ }^{6}$, Yi-Jun Lin ${ }^{7}$, \\ Su-Han You ${ }^{8}$ and Chung-Min Liao ${ }^{7^{*}}$
}

\begin{abstract}
Background: Lead-exposed workers may suffer adverse health effects under the currently regulated blood lead (BPb) levels. However, a probabilistic assessment about lead exposure-associated anemia risk is lacking. The goal of this study was to examine the association between lead exposure and anemia risk among factory workers in Taiwan.

Methods: We first collated BPb and indicators of hematopoietic function data via health examination records that included 533 male and 218 female lead-exposed workers between 2012 and 2014. We used benchmark dose (BMD) modeling to estimate the critical effect doses for detection of abnormal indicators. A risk-based probabilistic model was used to characterize the potential hazard of lead poisoning for job-specific workers by hazard index (HI). We applied Bayesian decision analysis to determine whether BMD could be implicated as a suitable BPb standard.

Results: Our results indicated that HI for total lead-exposed workers was 0.78 (95\% confidence interval: 0.50-1.26) with risk occurrence probability of $11.1 \%$. The abnormal risk of anemia indicators for male and female workers could be reduced, respectively, by $67-77 \%$ and $86-95 \%$ by adopting the suggested BPb standards of 25 and $15 \mu \mathrm{g} / \mathrm{dL}$.

Conclusions: We conclude that cumulative exposure to lead in the workplace was significantly associated with anemia risk. This study suggests that current BPb standard needs to be better understood for the application of lead-exposed population protection in different scenarios to provide a novel standard for health management. Low-level lead exposure risk is an occupational and public health problem that should be paid more attention.
\end{abstract}

Keywords: Blood lead, Benchmark dose, Probabilistic risk assessment, Health management, Decision analysis

\section{Background}

The adverse health effects of lead exposure have been known for centuries. Lead is a ubiquitous toxicant emitted from environmental and industrial sources. Exposure routes of lead uptake in the workplace include ingestion and inhalation of inorganic lead. Therefore, the major sources of lead exposure may come from dust, fume, and poor personal hygiene including eating and smoking through contaminated hands. Many biomonitoring methods are capable of measuring the bioaccumulation of lead in the human body [1]. Lead levels in bone, blood, urine, and exfoliated teeth are the major biomarkers of internal dose. Nowadays, blood lead (BPb) measurement is still the primary technique to investigate

\footnotetext{
* Correspondence: cmliao@ntu.edu.tw

${ }^{7}$ Department of Bioenvironmental Systems Engineering, National Taiwan University, Taipei 10617, Taiwan, ROC

Full list of author information is available at the end of the article
}

recent lead accumulation in the body. Recently, lead condensate in exhaled breath was also shown to be a suitable non-invasive biomarker of occupational exposure in recent years [2].

Lead poisoning is considered the most well characterized occupational disease. The inhaled/ingested lead can transport to the heart, bones, intestines, kidneys, reproductive, and nervous systems, causing tissuespecific adverse effects [3, 4]. Implements of industrial hygiene and control measures have significantly decreased workers' $\mathrm{BPb}$ concentrations over the last few decades [5, 6]. However, recent studies indicate that lead-exposed workers may suffer from adverse health effects under the current standards [7-9]. Low dose $\mathrm{BPb}(<20 \mu \mathrm{g} / \mathrm{dL})$ in chronically-exposed workers is still likely to be associated health outcomes, such as cognitive dysfunction, hypertension risk, and renal dysfunction $[9,10]$. In recent years, these low-dose toxic effects 
of lead have received considerable attention, thereby questioning the capability of the current standard for critical dose of lead to protect the health of leadexposed population. The issue not only in lead industries, but it also causes some problems in public health in several areas [11-14].

Adverse hematological effects are some of the manifestations of lead poisoning in lead workers. Chronic lead poisoning inhibits the ability to produce hemoglobin by interfering with enzymatic steps in the heme synthesis pathway and diminishes red blood cells, thereby increasing risk of anemia [15]. The absorption of lead can cause iron deficiency and may further cause anemia. Anemia associated with chronic lead exposure is a result of both interferings with heme biosynthesis and by decreasing red blood cell survival.

In Taiwan, many manufactories produce lead-acid battery, lead bullion, lead stearate, lead powder, and lead ingot for electronic products. Current health management limits for lead workers were set at 40 and $30 \mu \mathrm{g} / \mathrm{dL}$ for males and females, respectively. However, lead-exposed workers may suffer from adverse health effects under the current $\mathrm{BPb}$ reference. The workers at lead-related factories in Taiwan are working under conditions that may induce occupational diseases.

The main purpose of this study was to assess the risk of anemia for workers in lead factories and to provide a suggested $\mathrm{BPb}$ limit to improve health management for lead workers. A probabilistic risk assessment approach was used to estimate the $\mathrm{BPb}$ effect doses for abnormal hematological indicators and to assess anemia risk associated with exposure to lead. Bayesian statistics-based decision analysis was used to determine the hazard prevention probability when lead workers' $\mathrm{BPb}$ were controlled under the recommend health management level.

\section{Methods}

\section{Study population}

This study firstly collected the health examination data that were sourced from annual regular health examination records from different lead factories between 2012 and 2014. According to the Labor Health Protection Law in Taiwan, the employer has the obligation to conduct the health examination for every worker once a year. Lead workers also need to receive the special physical and medical examinations. The examination items were included the inspection of $\mathrm{BPb}$ and hematological indicators of hematocrit (Hct), hemoglobin ( $\mathrm{Hgb})$, red blood cell count (RBC), mean corpuscular volume (MCV), mean corpuscular hemoglobin $(\mathrm{MCH})$, and mean corpuscular hemoglobin concentration (MCHC) [16]. Some other information such as gender, birthdate, start working date and manufacturing area were also been recorded. Based on the Labor Health Protection
Law, lead workers were asked to complete the questionnaire of special physical and the medical examination that included five items of demographic data, working experience, past medical history, living habits, and selfperceived symptoms. To characterize exposure history, we collected birth dates, dates of employment and examination records from the subjects. Work experience was used to describe the past and current working processes to further characterize exposure history. According to these information, the job-specific exposure conditions were calculated based on the working areas for each lead worker.

The total of 533 male and 218 female lead-exposed workers' data were collected to construct the dataset, sourcing from 6 factories with different manufactory types (Table 1). The average ages of male and female workers were 43.7 (sd: 10.2) and 47.1 (8.6) yrs. All 533 male workers were working in the lead battery, lead stearate, and lead bullion factories, respectively. All 218 female workers were working in lead battery factories. Within a lead battery factory, the manufacturing areas were classified as casting, grinding, powder, filling, formatting, cutting, assembling, charging, packaging, or other off-site positions. The job-specific exposure conditions were calculated based on the working areas for lead workers.

\section{Benchmark dose-based effect analysis}

We used the health examination record to construct the dose-response relationships between $\mathrm{BPb}$ levels and adverse hematological indicators. We used correlation analysis is the preliminary exam in effect analysis that allows us to understand the strength between the effect factors and anemia-associated indicators. We used correlation analysis to investigate the relationships among hematological indicators, $\mathrm{BPb}$, and related confounders.

Hematological indicators have the reference ranges in the clinical medicine that can be used to diagnose the conditions of hematopoietic system. This study adopted these reference ranges to calculate the number and propotion of normal and abnormal lead workers in male and female populations. For estimating the critical effect dose of $\mathrm{BPb}$ for lead-associated abnormal hematological indicator, we employed the benchmark dose (BMD) models that have been used in many previous risk assessment studies [16].

We calculated the dichotomous response from quantal data using BMD models, as summarized in Table S1 (see Additional file 1). The benchmark response (BMR) was set to an abnormal proportion of $10 \%\left(\mathrm{BMR}_{10}\right)$ in the dose-response relationshi, as a conservative approach to protect the health of lead-exposed. 
Table 1 Basic statistics of age, working years, BPb levels, and indicators of hematopoietic function for 533 male and 218 female lead-exposed workers

\begin{tabular}{|c|c|c|c|}
\hline Item & Unit & Mean (SD) & Min - Max \\
\hline \multicolumn{4}{|l|}{ Basic information } \\
\hline Age & yrs & $43.7(10.2) / 47.1(8.6)^{a}$ & $21-65$ / 27-64 \\
\hline Working years & yrs & $11.8(10.9) / 13.4(9.7)$ & $0-38 / 1-42$ \\
\hline Blood lead & $\mu \mathrm{g} / \mathrm{dL}$ & $21.4(13.3) / 11.3(5.7)$ & $2.1-101.4 / 1.8-31.3$ \\
\hline \multicolumn{4}{|l|}{ Hematopoietic function } \\
\hline Hematocrit & $\%$ & $44.8(3.2) / 40.1(3.6)$ & $31.3-57.8 / 26.6-46.9$ \\
\hline Hemoglobin & $g / L$ & $15.11(1.2) / 13.1(1.4)$ & $10.5-18.8 / 7.9-15.5$ \\
\hline Red blood cell count & $\times 10^{6} / \mu \mathrm{L}$ & $5.16(0.50) / 4.6(0.4)$ & $3.73-7.44$ / 3.6-6.4 \\
\hline Mean corpuscular volume & $\mathrm{fl}$ & $87.4(7.1) / 87.6(8.6)$ & $57-102 / 49.4-97.1$ \\
\hline Mean corpuscular hemoglobin & $\mathrm{pg}$ & $29.5(2.9) / 28.7(3.4)$ & $17.5-38.6 / 14.1-33.9$ \\
\hline Mean corpuscular hemoglobin concentration & $\%$ & $33.8(1.3) / 32.7(1.3)$ & $29.2-38.9 / 28.1-36.1$ \\
\hline
\end{tabular}

aale/Female

\section{Rick characterization}

Health risk of anemia for workers at job-specific working areas was calculated by using a joint probability function combining the predicted $\mathrm{BMD}_{10}$ as acceptable risk limits and $\mathrm{BPb}$ concentration. We used a Monte Carlo (MC) approach to generate the large number of simulated samples of $\mathrm{BPb}$ and to understand the most likely $\mathrm{BPb}$ value in each job category. We considered the potential sources of variability and uncertainty in the $\mathrm{BPb}$ distributions as a probability density function based on measured values.

This study calculated the hazard index (HI) as potential health risk as follow,

$$
\mathrm{P}(\mathrm{HI})=\frac{\mathrm{P}(\mathrm{BPb})}{\mathrm{P}(\mathrm{BMD})}
$$

The estimated BMDs were further treated probabilistically by considering the $\mathrm{BMD}_{10}$ and $\mathrm{BMDL}_{10}$, representing the mean and lower levels of 95\% confidence interval $(\mathrm{CI})$, respectively. $\mathrm{HI}>1$ implies that unacceptable health risk of anemia will occur for lead-exposed workers in the specific working group and $\mathrm{HI}<1$ indicates acceptable health risk with the proportion of health effect $<10 \%$.

Total risk (TR) can be estimated by the HI for each job category as,

$$
\mathrm{TR}=\sum_{\mathrm{i}=1}^{\mathrm{n}}\left(H I_{\mathrm{i}} \times p_{\mathrm{i}}\right)
$$

where $p_{\mathrm{i}}$ is the proportion of lead-exposed worker in the specific job category. Thus, hazard occurrence probability can be calculated by using the proportion of simulated $\mathrm{HI}$ which value is greater than 1 .

The risk contribution of job $\left(\mathrm{R}_{\mathrm{job}}, \%\right)$ can be estimated as,

$$
\mathrm{R}_{\mathrm{job}}=\frac{\mathrm{HI}_{\mathrm{i}} \times p_{\mathrm{i}}}{\mathrm{TR}}
$$

\section{Bayesian decision analysis}

To determine whether the proposed BMD can be used as a novel $\mathrm{BPb}$ limit for lead exposed-associated risk management, this study applied a Bayesian decision approach that has been widely used in the probabilisticbased statistical method in decision making [17]. We used odds ratio (OR) to determine the efficiency of risk prevention by comparing the grouped populations whose $\mathrm{BPb}$ levels were under the current health management limits and the estimated BMDs. After that, this study conducted the product of binomial likelihood that sourced from collected health examination data as $Y_{0} \sim$ binomial $\left(\pi_{0}, n_{0}\right)$ and $Y_{1} \sim$ binomial $\left(\pi_{1}, n_{1}\right)$ with the parameters of interest as $\theta=\left(\pi_{0}, \pi_{1}\right)$ where $Y_{0}$ and $Y_{1}$ are the observed normal and abnormal individuals in indicators of hematopoietic function. The parameters of $\pi_{0}$ and $\pi_{1}$ are the ratio of normal and abnormal hematological indicators in the subpopulation number of $n_{0}$ and $n_{1}$, respectively. The OR was estimated as,

$$
\mathrm{OR}=\frac{\pi_{1}\left(1-\pi_{0}\right)}{\pi_{0}\left(1-\pi_{1}\right)}
$$

We assumed the beta priors for the occurred probabilities $\pi_{0}$ and $\pi_{1}$ with parameters $\left(a_{0}, b_{0}\right)$ and $\left(a_{1}, b_{1}\right)$, respectively. The posterior can be given by $\left(\pi_{0} \mid y\right) \sim$ beta $\left(y_{0}\right.$ $\left.+a_{0}, n_{0}+b_{0}\right)$ and $\left(\pi_{1} \mid y\right) \sim \operatorname{beta}\left(y_{1}+a_{1}, n_{1}+b_{1}\right)$. Estimation of the posterior distribution of ORs can be simply obtained by simulating the distribution of $f\left(\pi_{0} \mid y\right)$ and $f\left(\pi_{1} \mid y\right)$. Finally, hazard prevention probability was calculated by using the proportion of simulated ORs. To prevent the confounding factors that may cause abnormal hematological indicators with lower occupational lead 
exposure, this study adjusted the estimation of ORs by excluding the low-level $\mathrm{BPb}(<5 \mu \mathrm{g} / \mathrm{dL})$.

\section{Uncertainty and data analysis}

Statistics and regressions of this study were conducted in the open source language $\mathrm{R}$ (Version 3.1.1, The R Foundation for Statistical Computing). The $p$-value $<0.05$ was considered to be statistically-significant. The BMD models were performed by BMD software (Version 2.5.1, USEPA) and followed the guidelines from USEPA $[18,19]$. The Cochran-Armitage test for trend analysis was used to assess the presence of a doseresponse relationship. We chose the dose-response dataset with $p$-value $<0.05$ to perform subsequent data analysis.

The best-fitted model and associated BMD and BMDL for each dose-response relation were selected based on the Akaike's information criterion (AIC) and $p$-value of Chi-squared $\left(x^{2}\right)$. The AIC was defined as penalized likelihood function as $A I C=-2 \log L+2 p$ that $p$ was the number of parameters in the model and $L$ is the maximum likelihood value.

The quality of fit for BPb distributions in different job categories was judged by using classical goodness-of-fit statistics included $\chi^{2}$ and Kolmogrov-Smirnov statistics. This study took into account all BMD models that had large $p$-value from Pearson $\chi^{2}$ goodness-of-fit statistics. To integrate the risk estimates across different models, the model-averaging BMD was applied by calculating the weight $w_{\mathrm{k} .}$ for each model as [20],

$$
w_{k}=\frac{\exp \left(-0.5 A I C_{k}\right)}{\sum_{i=1}^{K} \exp \left(-0.5 A I C_{i}\right)} .
$$

Thus, the model-averaged BMD and BMDL can be calculated as $\mu(\mathrm{BMD})=\sum_{k=1}^{K} \mathrm{BMD}_{k} \cdot w_{k}$ and $\mu(\mathrm{BMDL})$ $=\sum_{k=1}^{K} \mathrm{BMDL}_{k} \cdot w_{k}$, respectively. We examined the overall resulting BMDs from different models to determine the most reliable $\mathrm{BMD}_{10}$ and $\mathrm{BMDL}_{10}$.

Uncertainty is a key factor in risk assessment that can influence the precision of risk estimation [21]. This study considered the uncertainty and its impact on the expected risk estimates that were quantified by $\mathrm{MC}$ simulation. Each simulation was carried out with 10,000 iterations to assure the stability of its probability distribution.

\section{Results}

\section{$\mathrm{BPb}$ distribution}

Figure 1 shows the ordering $\mathrm{BPb}$ level of lead workers in different working areas. Male workers in the lead battery manufacturing processes of grinding, cutting, and filling had relatively higher $\mathrm{BPb}$ concentrations than those in other working areas. Median $\mathrm{BPb}$ concentrations were

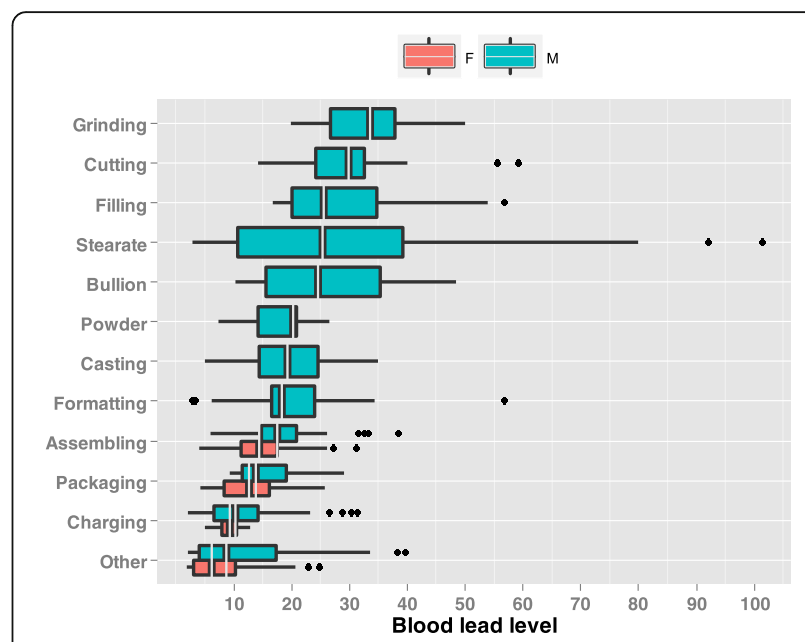

Fig. 1 Boxplots ordering the job-specific BPb levels for male and female workers in lead factories

estimated 24.5 and $25.3 \mu \mathrm{g} / \mathrm{dL}$ for male workers in facilities of lead bullion, and lead stearate, respectively. The highest $\mathrm{BPb}$ concentration was observed in lead stearate factories. Compared with male workers, female workers in lead battery factories had lower BPb levels.

The distributions of the abnormal number in hematological indicators are shown in Table 2. We found out that the abnormal proportion of indicator can exceed $20 \%$ for male workers in the exposure groups of grinding, powder, formatting, assembling, and charging, whereas the abnormal proportion may exceed $20 \%$ for female workers in every working group. Overall, the abnormal proportions ranged between 0 and $37.5 \%$ for each subgroup.

\section{Critical effect dose estimation}

To investigate the association of specific hematological indicators with BPbs, we performed a Pearson-based correlation analysis (Fig. 2). The BPb was significantly correlated with all hematological indicators, including Hct $(r=-0.38 ; p<0.001)$, Hgb $(r=-0.40 ; p<0.001)$, $\operatorname{RBC}(r=-0.18 ; p<0.05), \operatorname{MCV}(r=-0.19 ; p<0.01)$, $\mathrm{MCH}(r=-0.22 ; p<0.01)$, and $\mathrm{MCHC}(r=-0.18$; $p<0.05$ ) for male workers (Fig. 2a).

To determine the critical effect dose, we used BMD modeling to estimate the $\mathrm{BPb}$ levels that could associate with $10 \%$ abnormal proportion of each hematological indicator. Through Cochran-Armitage trend test, our results found that hematological indicators had significant dose-response trend with $\mathrm{BPb}$ concentration in male workers, including Hct $\left(\chi^{2}=3.336 ; p<0.01\right), \operatorname{Hgb}\left(\chi^{2}=1.741 ; p<0.05\right), \operatorname{MCV}\left(\chi^{2}=\right.$ 3.879; $p<0.001)$, and MCH $\left(\chi^{2}=3.343 ; p<0.001\right)$ (see Additional file 2: Tables S2 - S5). Among female workers, hematological indicators had significant doseresponse trend for Hct $\left(X^{2}=2.110 ; p<0.05\right)$, RBC 
Table 2 Job-specific number of workers and the related abnormal number of hematological indicators in each job

\begin{tabular}{ccccccccc}
\hline \multirow{2}{*}{ Job categories } & Gender & No. of & \multicolumn{5}{c}{ Abnormal no. of hematological indicator (\%) } \\
& & workers & Het & Hgb & RBC & MCV & MCH & MCHC \\
\hline Lead bullion & $\mathrm{M}$ & 12 & $0 / 0.0^{\mathrm{a}}$ & $0 / 0.0$ & $2 / 16.7$ & $3 / 25.0$ & $3 / 25.0$ & $1 / 8.3$ \\
Lead stearate & $\mathrm{M}$ & 93 & $11 / 11.8$ & $11 / 11.8$ & $7 / 7.5$ & $9 / 9.7$ & $10 / 10.8$ & $1 / 1.1$ \\
& $\mathrm{M}$ & 428 & $60 / 14.0$ & $48 / 11.2$ & $57 / 13.3$ & $46 / 10.7$ & $62 / 14.5$ & $54 / 12.6$ \\
Lead battery & $\mathrm{F}$ & 218 & $35 / 16.1$ & $26 / 11.9$ & $27 / 12.4$ & $20 / 9.2$ & $27 / 12.4$ & $42 / 19.3$ \\
Casting & $\mathrm{M}$ & 43 & $2 / 4.7$ & $3 / 7.0$ & $7 / 16.3$ & $6 / 14.0$ & $6 / 14.0$ & $6 / 14.0$ \\
Grinding & $\mathrm{M}$ & 8 & $1 / 12.5$ & $0 / 0.0$ & $1 / 12.5$ & $2 / 25.0$ & $3 / 37.5$ & $0 / 0.0$ \\
Powder & $\mathrm{M}$ & 16 & $1 / 6.3$ & $1 / 6.3$ & $2 / 12.5$ & $3 / 18.8$ & $3 / 18.8$ & $4 / 25.0$ \\
Filling & $\mathrm{M}$ & 36 & $4 / 11.1$ & $3 / 8.3$ & $4 / 11.1$ & $4 / 11.1$ & $6 / 16.7$ & $3 / 8.3$ \\
Formatting & $\mathrm{M}$ & 37 & $8 / 21.6$ & $8 / 21.6$ & $3 / 8.1$ & $4 / / 10.8$ & $5 / 13.5$ & $3 / 8.1$ \\
Cutting & $\mathrm{M}$ & 47 & $5 / 10.6$ & $3 / 6.4$ & $7 / 14.9$ & $4 / 8.5$ & $6 / 12.8$ & $5 / 10.6$ \\
Assembling & $\mathrm{M}$ & 48 & $10 / 20.8$ & $5 / 10.4$ & $4 / 8.3$ & $1 / 2.1$ & $2 / 4.2$ & $2 / 4.2$ \\
& $\mathrm{~F}$ & 93 & $19 / 20.4$ & $10 / 10.8$ & $14 / 15.1$ & $7 / 7.5$ & $10 / 10.8$ & $17 / 18.3$ \\
Charging & $\mathrm{M}$ & 40 & $8 / 20.0$ & $7 / 17.5$ & $4 / 10.0$ & $6 / 15.0$ & $9 / 22.5$ & $3 / 7.5$ \\
& $\mathrm{~F}$ & 45 & $4 / 8.9$ & $5 / 11.1$ & $4 / 8.9$ & $3 / 6.7$ & $4 / 8.9$ & $9 / 20.0$ \\
Packaging & $\mathrm{M}$ & 18 & $1 / 5.6$ & $1 / 5.6$ & $2 / 11.1$ & $2 / 11.1$ & $3 / 16.7$ & $2 / 11.1$ \\
& $\mathrm{~F}$ & 15 & $2 / 13.3$ & $1 / 6.7$ & $3 / 20.0$ & $2 / 13.3$ & $3 / 20.0$ & $2 / 13.3$ \\
Other & $\mathrm{M}$ & 135 & $20 / 14.8$ & $17 / 12.6$ & $23 / 17.0$ & $14 / 10.4$ & $19 / 14.1$ & $26 / 19.3$ \\
& $\mathrm{~F}$ & 65 & $10 / 15.4$ & $10 / 15.4$ & $6 / 9.2$ & $8 / 12.3$ & $10 / 15.4$ & $14 / 21.5$ \\
\hline
\end{tabular}

Percentage (\%)

(white: $<10 \%$, light gray: $10-20 \%$, and dark gray: $>20 \%$ )

$\left(\mathrm{X}^{2}=1.849 ; p<0.05\right), \mathrm{MCV}\left(\mathrm{x}^{2}=1.887 ; p<0.05\right)$, and $\mathrm{MCH}$ $\left(\chi^{2}=2.472 ; p<0.01\right)$ (see Additional file 2: Tables S6 - S9).

The model averaging $\mathrm{BMD}_{10}$ estimates were 53.5 $\left(\mathrm{BMDL}_{10}\right.$ : 40.5), 60 (44.5), 37.8 (22.1), and $42.0 \mu \mathrm{g} / \mathrm{dL}$ (28.8) for Hct, $\mathrm{Hgb}, \mathrm{MCV}$, and $\mathrm{MCH}$ for male workers, respectively (Tables S2 - S5). Among female workers, model averaging $\mathrm{BMD}_{10}$ estimates were $8.6\left(\mathrm{BMDL}_{10}\right.$ : 5.5), 9.8 (6.3), 12.1 (9.4), and $10.7 \mu \mathrm{g} / \mathrm{dL}$ (7.9) for Hct, $\mathrm{RBC}, \mathrm{MCV}$, and $\mathrm{MCH}$, respectively (Tables S6 - S9).

Figure $3 \mathrm{a}$ shows that $\mathrm{BMD}_{10}$ were strongly correlated with $\mathrm{BMDL}_{10}$ for male $(r=0.69)$ and female $(r=0.82)$ workers. Based on MC simulation, the BMDs were depicted as a probability density function of normal distribution that average $\mathrm{BMD}_{10}$ were $48.39 \pm 11.58$ (mean $\pm \mathrm{sd}$ ) and $10.26 \pm 1.98 \mu \mathrm{g} / \mathrm{dL}$ for male and female workers, respectively (Fig. 3b).

\section{Anemia risk estimates}

We found that the highest hazard occurrence probability was in male grinding workers with median HI of 1.00 (95\% CI: 0.39-1.80) (Fig. 4). For female workers, assembling and packaging work groups had relatively higher hazard occurrence probabilities of $80 \%$ and $60 \%$ with the median HIs of $1.48(0.47-2.67)$ and $1.32(0.43-3.16)$, respectively. The overall risk in $\mathrm{HI}$ for lead-exposed workers was $0.78(0.50-1.26)$ with hazard occurrence probability of $11 \%$. Risk contribution analysis indicated that female workers in the assembling group contributed a significant high risk to the total population, with a contribution proportion of $31.5 \%$. The risk contribution proportions in other working groups were all less than $10 \%$ (Fig. 4).

\section{Health management-based risk decision}

Based on the probability distribution (Fig. 3b), we examined the simulated $\mathrm{BMD}_{10}$ of $\mathrm{BPb}$ concentrations as recommended health management limits that were set at 25 and $35 \mu \mathrm{g} / \mathrm{dL}$ for male workers. The recommended standards for female workers were set at 10 and $15 \mu \mathrm{g} /$ $\mathrm{dL}$. We used the recommended BMDs to compare with the current health management limits that were 40 and $30 \mu \mathrm{g} / \mathrm{dL}$ for male and female workers, respectively.

Figure 5 shows the results of decision analysis. Confounding was addressed using data stratification. ORs 


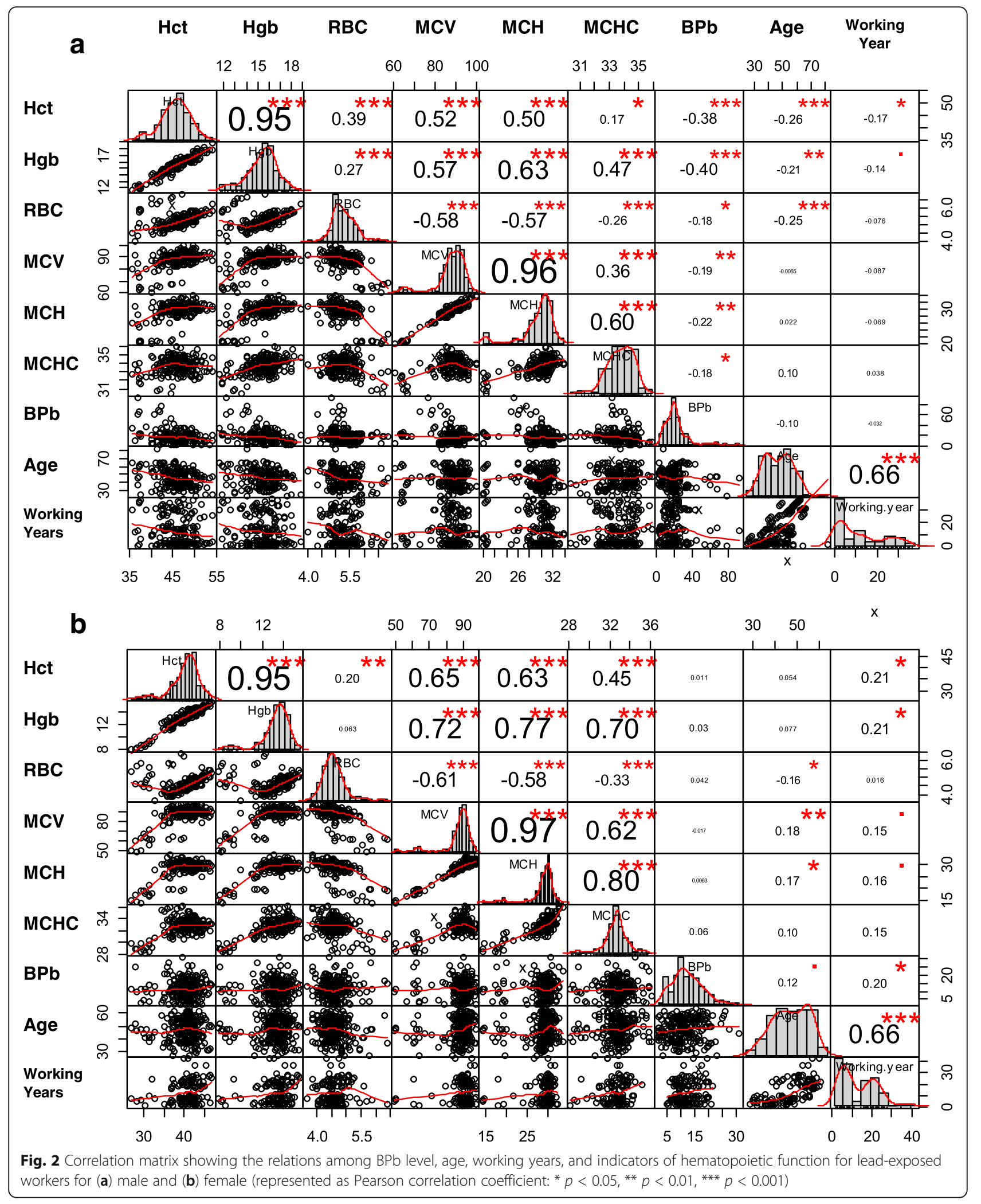




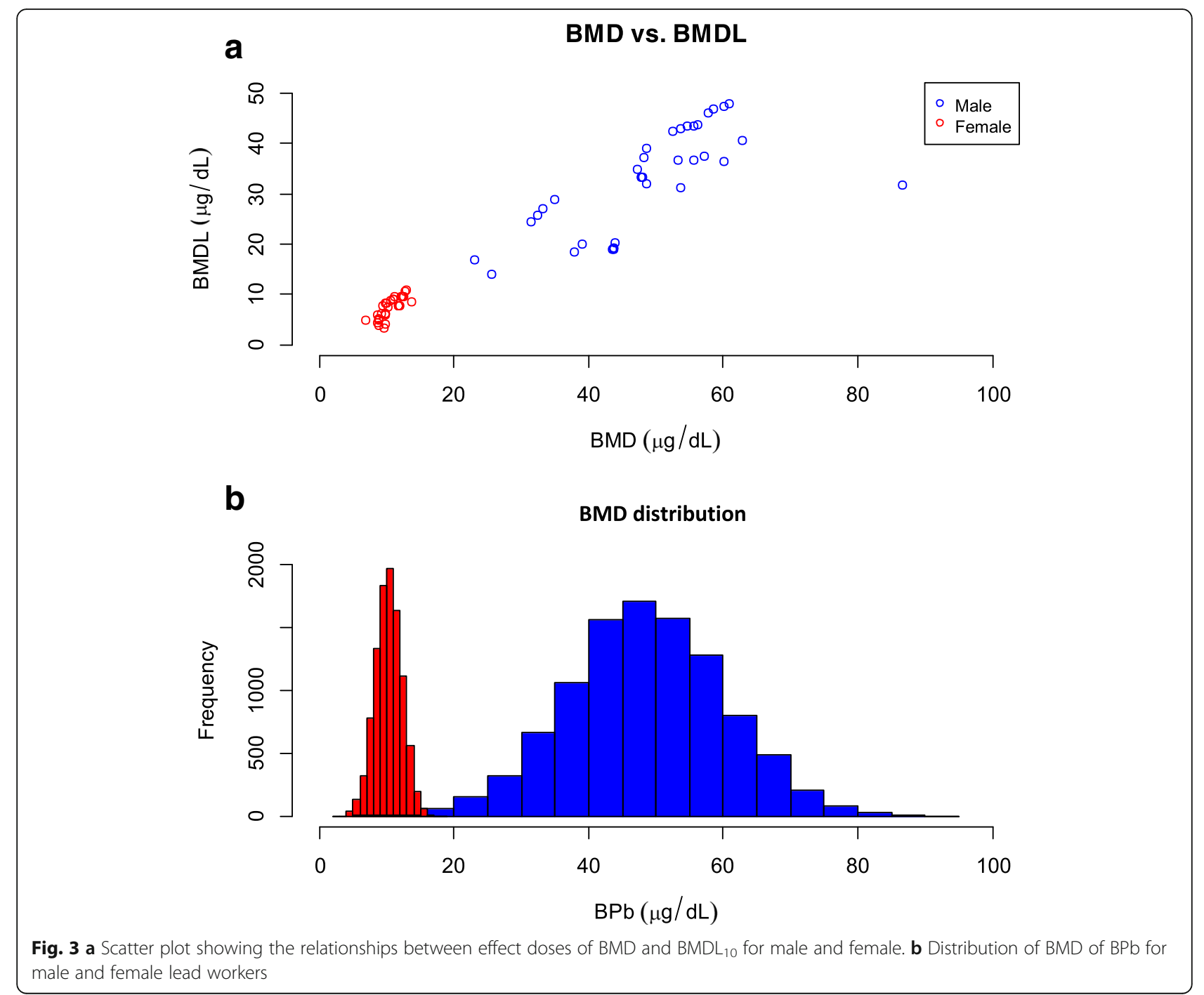

and adjusted ORs in male workers were 1.00 (95\% CI: $0.84-1.18)$ and $1.10(0.85-1.41)$ by using $35 \mu \mathrm{g} / \mathrm{dL}$ as $\mathrm{BPb}$ limit with the hazard prevention probabilities of $50.6 \%$ and $76.2 \%$ under unadjusted and adjusted scenarios, respectively. Moreover, when we adopted $25 \mu \mathrm{g} / \mathrm{dL}$ as $\mathrm{BPb}$ limits, the results of ORs and adjusted ORs were $1.04(0.88-1.23)$ and $1.09(0.87-1.37)$ with the hazard prevention probabilities of $67.0 \%$ and $76.9 \%$ under unadjusted and adjusted scenarios, respectively. ORs and adjusted ORs were $1.19(0.88-1.59)$ and $1.38(0.95-1.97)$ for female workers by using $15 \mu \mathrm{g} / \mathrm{dL}$ as $\mathrm{BPb}$ limit with the hazard prevention probabilities of $85.5 \%$ and $95.0 \%$ under unadjusted and adjusted scenarios, respectively (Fig. 5). It can be seen that estimated ORs were relatively higher when we adopted $15 \mu \mathrm{g} / \mathrm{dL}$ as BPb limit. The estimated ORs and adjusted ORs, respectively, were 0.96 $(0.75-1.20)$ and $0.91(0.70-1.18)$ when using $10 \mu \mathrm{g} / \mathrm{dL}$ as $\mathrm{BPb}$ limit. The hazard prevention probabilities were estimated $32.0 \%$ and $22.9 \%$ under unadjusted and adjusted scenarios, respectively.

\section{Discussion}

\section{Risk quantification and decision}

This study focuses on lead exposure-related anemia risk. Therefore, we used hematological indicators to represent $\mathrm{BPb}$-induced anemia. The Hct, Hgb, and RBC were representative indicators of lead-associated occupational anemia and can be used to evaluate the critical $\mathrm{BPb}$ levels to protect lead workers [16]. In addition to common indicators, our study also applied the measurements of $\mathrm{MCV}, \mathrm{MCH}$, and $\mathrm{MCHC}$, which were calculated by three original indicators to estimate the possible critical values.

This study found that BPb-related hematological effects of anemia were consistent with previous studies $[16,22]$. Even though numerous studies have 


\begin{tabular}{|c|c|c|c|c|c|}
\hline Job categories & Hazard index $(95 \% \mathrm{Cl})$ & & & $\begin{array}{c}\text { Hazard occurrence } \\
\text { probability (\%) }\end{array}$ & \begin{tabular}{|c|} 
Risk \\
contribution (\%)
\end{tabular} \\
\hline Lead bullion & $0.82(0.25-2.07)$ & $\longrightarrow$ & 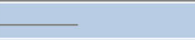 & 26.6 & 1.4 \\
\hline Lead stearate & $0.93(0.11-3.67)$ & $\longrightarrow$ & & 29.0 & 9.5 \\
\hline \multicolumn{6}{|l|}{ Lead battery } \\
\hline Casting & $0.60(0.13-1.22)$ & $\longrightarrow$ & 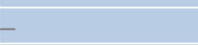 & 7.6 & 4.2 \\
\hline Grinding & $1.00(0.39-1.80)$ & $\longrightarrow$ & 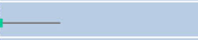 & 44.4 & 1.3 \\
\hline Powder & $0.57(0.27-1.00)$ & $\rightarrow$ & & 2.7 & 1.4 \\
\hline Filling & $0.87(0.38-1.77)$ & $\longrightarrow$ & 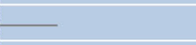 & 28.7 & 4.8 \\
\hline Formatting & $0.61(0.10-1.24)$ & $\Longrightarrow$ & - & 9.4 & 3.6 \\
\hline Cutting & $0.90(0.44-1.69)$ & $\longrightarrow$ & 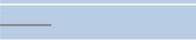 & 30.2 & 6.6 \\
\hline \multirow[b]{2}{*}{ Assembling } & $0.57(0.25-1.14)$ & $\because-$ & & 4.8 & 4.2 \\
\hline & $1.48(0.47-2.67)$ & 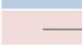 & 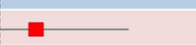 & 79.5 & 31.5 \\
\hline \multirow[b]{2}{*}{ Charging } & $0.37(0.07-1.18)$ & $\rightarrow$ & - & 4.4 & 1.9 \\
\hline & $0.94(0.51-1.49)$ & $\longrightarrow$ & - & 36.0 & 9.7 \\
\hline \multirow[b]{2}{*}{ Packaging } & $0.47(0.22-0.89)$ & $\rightarrow$ & & 0 & 1.3 \\
\hline & $1.32(0.43-3.16)$ & $\underline{-}$ & $=$ & 60.0 & 4.1 \\
\hline \multirow[b]{2}{*}{ Other } & $0.35(0.05-1.30)$ & $\rightarrow$ & - & 4.9 & 5.6 \\
\hline & $0.81(0.13-2.81)$ & $\longrightarrow$ & 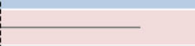 & 26.1 & 9.1 \\
\hline Total & $0.78(0.50-1.26)$ & - & & 11.1 & \\
\hline
\end{tabular}

Fig. 4 Forest plot showing the estimated hazard index with 95\% confidence intervals and relative risk contribution for each working group. Female workers are represented by light gray

demonstrated that $\mathrm{BPb}$ can induce adverse effects to the hematological system, Pourabdian et al. [23] found that indicators of $\mathrm{Hgb}, \mathrm{MCV}$, and white blood cell cell did not display concentration-dependence on $\mathrm{BPb}$ levels. Some confounders such as menstruation, smoking, and working status may influence the relationships between $\mathrm{BPb}$ and hematological indicators.

In this study, the BMD model gave us an opportunity to estimate the critical effect dose for $\mathrm{BPb}$-associated anemia in workers. BMD modeling has been utilized as a more precise mathematical approach for performing toxicological risk assessment [24]. Compare to the traditional method of using NOAEL (No observed adverse effect level) or LOAEL (Lowest observed adverse effect level), BMD modeling can be further applied to model prediction in the toxicological and epidemiological investigation.

Overall, the BMD models provide more accurate and precise value by using the computational approach,

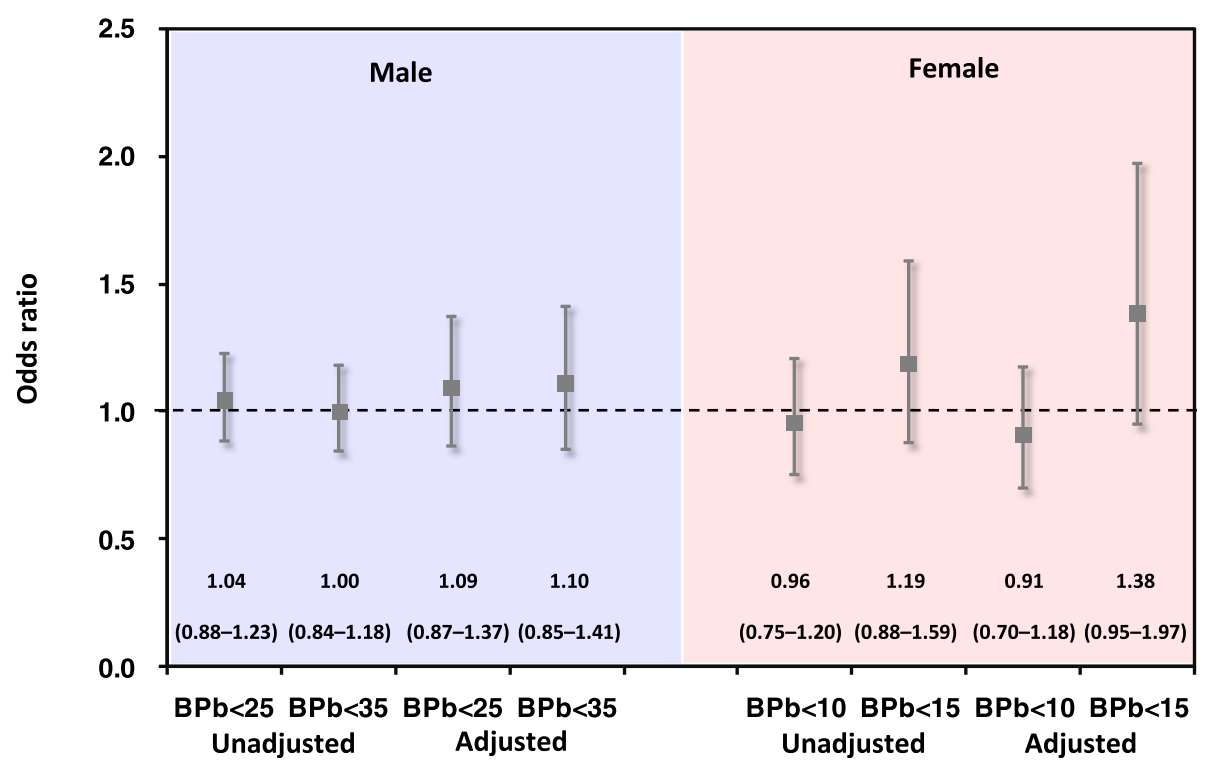

Fig. 5 Bayesian analysis-based ORs determining the available of calculated $\mathrm{BMD}_{10}$ as novel BPb limit. Bars indicate $95 \%$ confidence intervals. Dotted line, null value $(\mathrm{OR}=1.0)$ 
which considers the uncertainty from the epidemiological information and mathematical models. Our results show that $\mathrm{BMD}_{10}$ and $\mathrm{BMDL}_{10}$ estimates ranged from 23 to 87 and $15-48 \mu \mathrm{g} / \mathrm{dL}$ for male workers after adjusting for of age and working years. Our estimation of $\mathrm{BMD}_{10}$ was similar to those reported by Karita et al. [16], which ranged from 48 to $73 \mu \mathrm{g} / \mathrm{dL}$. Further, our $\mathrm{BMDL}_{10}$ estimates were consistent with their results, which ranged from 33 to $49 \mu \mathrm{g} / \mathrm{dL}$.

According to the recent statement from American College of Occupational and Environmental Medicine (ACOEM), BPb is still a reliable and wide-used biomonitoring indicator for the health effects associated with lead exposure. The most compelling epidemiology evidence shows that the increased cardiovascular morbidity and mortality in populations with $\mathrm{BPb}$ in the low to medium range of 10 to $20 \mu \mathrm{g} / \mathrm{dL}[25,26]$. The most notable effect is the increased cardiovascular risks at these $\mathrm{BPb}$ levels, but the adverse pregnancy outcomes and other effects may also occur.

Risk assessment results demonstrated that lead workers are likely to work in unsafe workplaces. Unacceptable hazard occurrence probability was approximately $11.1 \%$ for total lead workers. Female workers in the assembling group had a higher risk of 79.5\%, resulting in hematological effects, which may exceed the acceptable level. Risk contribution was $31.5 \%$ within total lead workers. However, the highest hazard contribution in male lead workers was estimated at only $9.5 \%$ in the grinding group. It seems that appropriate engineering control measures and hygiene strategies still play an important role in limiting lead exposure for female lead workers [27].

To determine whether the estimated critical values of $\mathrm{BPb}$ can be used as the novel limit for health management, this study successfully applied a Bayesian analysis approach integrated with $\mathrm{MC}$ simulation to estimate the uncertainty and reliability of risk control efficiency. Our approach had also been widely used in exposure analysis and risk decision-making in environmental and occupational health research $[28,29]$.

To determine the $\mathrm{BPb}$ levels in health management, we examined the simulated BPbs that were set at 25 and $35 \mu \mathrm{g} / \mathrm{dL}$ for male workers. This study also examined the $\mathrm{BPb}$ levels at 10 and $15 \mu \mathrm{g} / \mathrm{dL}$ for female workers. Our results found out that there were slight differences when considering these two $\mathrm{BPb}$ levels for male workers. Although the ORs and hazard prevention probabilities of a BPb level at $25 \mu \mathrm{g} / \mathrm{dL}$ were higher than those of a $\mathrm{BPb}$ level at $35 \mu \mathrm{g} / \mathrm{dL}$, it seems that the improving efficiency had reached the theoretical level. Therefore, the suitable $\mathrm{BPb}$ level of male workers for health management of anemia can be set in this interval. The $\mathrm{BPb}$ hematological BMDs for female workers were lower than male, indicating that female workers are more vulnerable for lead-related anemia than male. We found that $\mathrm{BPb}$ level at $15 \mu \mathrm{g} / \mathrm{dL}$ could be used as a suitable health management limited rather than $10 \mu \mathrm{g} / \mathrm{dL}$.

Our results also revealed that $95 \%$ CIs of Bayesian analysis-based ORs all cover the value of 1, indicating that the risk control efficiency may be slightly insignificant. However, the results from hazard prevention probabilities showed that there were nearly 50-70\% probabilities of improving the lead-related anemia by restraining $\mathrm{BPb}$ limit up to $25-35 \mu \mathrm{g} / \mathrm{dL}$ for male workers. The hazard prevention probabilities for female workers were $85.5-95.0 \%$ when BPb limit of $15 \mu \mathrm{g} / \mathrm{dL}$ was adopted. Thus, the anemia risk can also be reduced when a more stringent $\mathrm{BPb}$ level is adopted.

\section{Limitations and implications}

Our study provides the health protection guideline of $\mathrm{BPb}$ level in lead workers, which can be used to quantify anemia risk associated with lead exposure. This study did not focus on the exposure assessment of airborne lead. Compared with environmental monitoring of airborne lead concentration and permissible exposure level, $\mathrm{BPb}$ is more reliable and can be used to determine gender-specific health effects of lead. In addition, the airborne lead cannot fully reflect the health risk if the company successfully implements personal protection equipment and industrial hygiene.

This study could not investigate and control the other possible sources of lead exposure outside the work and get the complete information on previous experience of lead-related work. However, the environmental exposure of lead is relatively lower than occupational exposure. This study focuses on the dose-response relationship between $\mathrm{BPb}$ concentration and the hematological indicators from regular health examination. The $\mathrm{BPb}$ was mainly sourced from the current workplace. Therefore, we assumed that the cumulative $\mathrm{BPb}$ that sourced from workplace or other area can be associated with the change of the hematological indicators.

We recommend that male and female workers' $\mathrm{BPb}$ over 25 and $15 \mu \mathrm{g} / \mathrm{dL}$ should be considered to health management and exposure control. Lead-exposed workers need to be continuously controlled and reduce their $\mathrm{BPb}$ even if levels are under the current limits of $40 / 30 \mu \mathrm{g} / \mathrm{dL}$ for male/female workers. Flora et al. [30] reported that $\mathrm{BPb}$ levels of $10-20 \mu \mathrm{g} / \mathrm{dL}$ could precipitate anemia. The possible threshold of lead-associated anemia was also proposed by previous studies, which was approximately $20 \mu \mathrm{g} / \mathrm{dL}$ for lead workers [11, 16]. By contrast, our study found that BPb-related hematological effects may display gender-specificity due to inter-individual variability. Furthemore, there is no 
evidence of a safe exposure level for renal and cardiac effects associated with exposure to lead [31, 32].

According to our correlation analysis, we found that $\mathrm{BPb}$ had significantly negative correlations with hematological indicators in male workers. However, this correlation was not observed in female workers. This result might due to the fact that female workers had relatively lower $\mathrm{BPb}$ levels compared to males. Moreover, we were unable to collect information about the menstruation or pregnancy from our collated data for female workers. This data gap may influence our risk estimation results. The constructed dose-response relationship was an atypical S-shape in our effect analysis. We observed some abnormal hematological indicators in female workers who had lower BPb concentrations, an effect which may have been due to menstruation or pregnancy. Nonetheless, BPb levels in female workers needs to be carefully revised in order to prevent the lead-related anemia risk.

In addition to hematological effects of anemia, health effects of low-dose lead also include hypertension, cognitive dysfunction, renal, and reproductive effects. Lead may also be genotoxic [33, 34]. Neuropsychological effects of lead toxicity were also determined to be a common occupational hazard of lead toxicity [35]. Neurotoxic effects in lead-exposed workers were observed at $\mathrm{BPb}$ level below $20 \mu \mathrm{g} / \mathrm{dL}$, which was a more sensitive toxicity phenotype compared to other leadinduced adverse effects. Ahmad et al. [10] found that $\mathrm{BPb}$ was associated with hypertension and anemia for lead acid battery workers. Therefore, lead workers might suffer from illnesses associated with low-level lead exposure.

Computational approaches are a useful research tool in the health risk assessment of chemical exposure, including heavy metal [36]. A computational modeling approach was used to estimate airborne lead concentrations by using $\mathrm{BPb}$ levels [37]. OEHHA [37] used a computational approach and recommended that the BPb level should be between 5 to $10 \mu \mathrm{g} / \mathrm{dL}$ for workers over 40 years of working in a factory. Thus, the 8-h time-weighted-average airborne lead concentrations must not exceed $2.1 \mu \mathrm{g} / \mathrm{m}^{3}$. The permissible exposure limit (PEL) is $50 \mu \mathrm{g} / \mathrm{m}^{3}$ in Taiwan. Therefore, stringent PEL and personal hygiene strategy should be considered to reduce exposure to airborne lead.

Our study found that female workers had lower lead effect dose than male workers, suggesting that, compared to males, female workers are likely to have a higher risk of lead-induce anemia. In Taiwan, the Occupational Safety and Health Act suggests that pregnant women should stop working in the current lead-exposed workplace and prohibits them to work until one year after childbirth. Kosnett [8] recommended that women who are or may become pregnant and have a $\mathrm{BPb}>5 \mu \mathrm{g} / \mathrm{dL}$ should reduce their exposure to lead.

This study applied the model averaging method to integrate BMD estimates across multiple models. It has been used as an effective method for estimating the model uncertainty in BMD estimation. The model averaging method has also been widely applied to dichotomous dose-response relationships in a variety of risk assessment contexts such as occupational and epidemiological studies [38, 39]. However, several limitations may affect the accuracy of BMD estimation. Wheeler and Bailer [38] indicated that the "average-model" method often failed to adequately cover the true BMD when a linear or near linear dose-responses was modeled. The model averaging and the corresponding BMD and BMDL are potentially biased in low-dose scenarios.

The observed average $\mathrm{BPb}$ levels were much lower than the current health management limits in this study. However, this study still found some workers with hematological effects even though the $\mathrm{BPb}$ were under the permissible level. The proportions of lead working population with abnormal hematological indicators were estimated $>10 \%$ in each job category. Thus, we found that workers with lower $\mathrm{BPb}$ level $(<20 \mu \mathrm{g} / \mathrm{dL})$ had lower proportions of the abnormal population in hematological indicators. We also found out that some lead workers may still work in an unsafe condition with risk estimates of $\mathrm{HI}>1$, especially for female workers. It would be better to establish a new occupational strategy and enhance the education and training to reduce the $\mathrm{BPb}$ concentrations and subsequent hematotoxicity. Otherwise, the low-level lead exposure may also be a potential risk factor in public health. Our research framework can also be applied to assess other lead induced-adverse health effects in exposed population. Furthermore, a long-term follow-up investigation is urgently needed to characterize lead-associated adverse health effects.

\section{Conclusions}

This study showed that hematopoietic effects for male and female lead-exposed workers are observed even when $\mathrm{BPb}$ concentrations were under the current health management levels. By using the probabilistic risk assessment approach, our result showed that some leadexposed workers were likely to have unsafe levels of $\mathrm{BPb}$. The BMDs for lead exposed-induced health effects provided the novel limits on $\mathrm{BPb}$ for health management. Our results suggest that the current $\mathrm{BPb}$ limit needs to be better characterized to better protect the health of lead-exposed population. Low-level lead exposure risk is an occupational and public health problem that should be paid more attention. 


\section{Additional files}

Additional file 1: Table S1. Summary of the Benchmark dose (BMD) models used in this study. (DOCX $32 \mathrm{~kb}$ )

Additional file 2: Table S2-S9. Fitted quantal model for male leadexposed workers. (DOCX 27 kb)

\section{Abbreviations}

BMD: Benchmark dose; BMR: Benchmark response; BPb: Blood Lead; Hct: Hematocrit; Hgb: Hemoglobin; HI: Hazard index; LOAEL: Lowest observed adverse effect level; MC: Monte Carlo; MCH: Mean corpuscular hemoglobin; MCHC: Mean corpuscular hemoglobin concentration; MCV: Mean corpuscular volume; NOAEL: No observed adverse effect level; OR: Odds ratio; PEL: Permissible exposure limit; RBC: Red blood cell; TR: Total risk

\section{Acknowledgments}

The authors thank all members of Biosystems Modeling and Control Lab, Department of Bioenvironmental Systems Engineering, National Taiwan University, for their contribution to this work. We thank Dr. Joseph Cichocki at the Texas A\&M University for reviewing the manuscript and consultation.

\section{Funding}

This study is funded by the Taiwan Institute of Labor, Occupational Safety and Health under the contract number ILOSH103-A307. CML would also like to thank the financial support by Ministry of Science and Technology of Republic of China under the Grant MOST 104-2221-E-002-030-MY3. The funding body had no role in the design of the study, the collection, analysis, and interpretation of data, or the writing of the manuscript. The authors assume full responsibility for the content of the paper.

\section{Availability of data and materials}

The data that support the findings of this study are available from the lead factories in Taiwan but restrictions apply to the availability of these data, which were used under license for the current study, and so are not publicly available. Data are however available from the authors upon reasonable request and with permission of the lead factories in Taiwan.

\section{Authors' contributions}

$\mathrm{NHH}$ performed research concept design, data interpretation, manuscript preparation, and overall responsibility for study data. CSH searched the literature, reviewed the literature and made substantial contributions to conception and design. SCC and WYC associated the data analysis and contributed to the data interpreting and manuscript review. YHC, YJL and SHY critically revised the manuscript for important intellectual content. CML contributed research concept, manuscript writing and tables/figures fabricating. All authors read and approved the final manuscript.

\section{Authors' information}

$\mathrm{NHH}$ is a postdoctoral research fellow in Department of Veterinary Integrative Biosciences in Texas A\&M University. SHC is an assistant research fellow in Institute of Labor, Occupational Safety and Health, Ministry of Labor. SCC is a Professor in Department of Public Health, Chung Shan Medical University. WYC is an associate professor in Department of Biomedical Science and Environmental Biology in Kaohsiung Medical University. YHC is a postdoctoral research fellow in Institute of Computational Comparative Medicine, Department of Anatomy and Physiology, College of Veterinary Medicine, Kansas State University. YJL is a postdoctoral research fellow in Department of Bioenvironmental Systems Engineering, National Taiwan University. SHY is a postdoctoral research fellow in National Environmental Health Research Center, National Health Research Institutes. CML is a distinguished professor in Department of Bioenvironmental Systems Engineering, National Taiwan University.

\section{Competing interests}

The authors declare that they have no competing interests.

\section{Consent for publication}

Not applicable.

\section{Ethics approval and consent to participate}

Our study protocol was approved by the Institutional Review Boards I of the Tri-Service General Hospital, National Defense Medical Center (TSGHIRB: A-1-103-05-004). The study used non-identifiable data in all data analysis. All identifications such as name and job id were removed by the lead factories and Taiwan Institute of Labor, Occupational Safety and Health. Thus, no formal consent was required for our study as we performed a secondary analysis of existing data.

\section{Publisher's Note}

Springer Nature remains neutral with regard to jurisdictional claims in published maps and institutional affiliations.

\section{Author details}

'Department of Veterinary Integrative Biosciences, College of Veterinary Medicine and Biomedical Sciences, Texas A\&M University, College Station, TX 77845, USA. ${ }^{2}$ Institute of Labor, Occupational Safety and Health, Ministry of Labor, New Taipei City 22143, Taiwan, ROC. ${ }^{3}$ Department of Public Health, Chung Shan Medical University, Taichung 40242, Taiwan, ROC. ${ }^{4}$ Department of Family and Community Medicine, Chung Shan Medical University Hospital, Taichung 40242, Taiwan, ROC. ${ }^{5}$ Department of Biomedical Science and Environmental Biology, Kaohsiung Medical University, Kaohsiung 80708, Taiwan, ROC. ${ }^{6}$ Institute of Computational Comparative Medicine, Department of Anatomy and Physiology, College of Veterinary Medicine, Kansas State University, Manhattan, Kansas 66506, USA. DDepartment of Bioenvironmental Systems Engineering, National Taiwan University, Taipei 10617, Taiwan, ROC. ${ }^{8}$ National Environmental Health Research Center, National Health Research Institutes, Miaoli County 35053, Taiwan, ROC.

Received: 24 October 2016 Accepted: 26 April 2017

Published online: 05 May 2017

\section{References}

1. Barbosa F, Tanus-Santos JE, Gerlach RF, Parsons PJ. A critical review of biomarkers used for monitoring human exposure to lead: advantages, limitations, and future needs. Environ Health Perspect. 2005;113:1669-74.

2. Félix PM, Almeida SM, Pinheiro T, Sousa J, Franco C, Wolterbeek HT. Assessment of exposure to metals in lead processing industries. Int J Hyg Environ Health. 2013:216:17-24.

3. Liu KS, Hao JH, Zeng Y, Dai FC, Gu PQ. Neurotoxicity and biomarkers of lead exposure: a review. Chin Med Sci J. 2013;28:178-88.

4. Wu HM. Lin-Tan DT, Wang ML, Huang HY, Lee CL, Wang HS, Soong YK. Lin $J$ Lead level in seminal plasma may affect semen quality for men without occupational exposure to lead Reprod Biol Endocrin. 2012;10:91.

5. Fairfax R, Kilens G. Lead control in a bronze foundry. Appl Occup Environ Hyg. 1995;10:228-30.

6. Koh DH, Nam JM, Graubard BI, Chen YC, Locke SJ, Friesen MC. Evaluating temporal trends from occupational lead exposure data reported in the published literature using meta-regression. Ann Occup Hyg. 2007;51:665-78.

7. Schwartz BS, Hu H. Adult lead exposure: time for change. Environ Health Perspect. 2007;115:451-4.

8. Kosnett MJ, Wedeen RP, Rothenberg SJ, Hipkins KL, Materna BL, Schwartz BS, Hu H, Woolf A. Recommendations for medical management of adult lead exposure. Environ Health Perspect. 2007;115:463-71.

9. Shih RA, Hu H, Weisskopf MG, Schwartz BS. Cumulative lead dose and cognitive function in adults: a review of studies that measured both blood lead and bone lead. Environ Health Perspect. 2007;115:483-92.

10. Ahmad SA, Khan MH, Khandker S, Sarwar AFM, Yasmin N, Faruquee MH, Yasmin R. Blood lead levels and health problems of lead acid battery workers in Bangladesh. Scientific World J. 2014;974104

11. Murata K, Iwata T, Dakeishi M, Karita K. Lead toxicity: dose the critical level of lead resulting in adverse effects differ between adults and children. J Occup Health. 2009:51:1-12.

12. Riva MA, Lafranconi A, D'Orso Ml, Cesana G. Lead poisoning: historical aspects of a paradigmatic "occupational and environmental disease". Saf Health Work. 2012;3:11-6.

13. United Nations Environment Programme. UNEP, lead in enamel decorative paints. A Nine Country Study. Nairobi: National Paint Testing Results; 2013.

14. Keramati MR, Manavifar L, Badiee Z, Sadeghian MH, Farhangi H, Mood MB. Correlation between blood lead concentration and iron deficiency in Iranian children. Niger Med J. 2013;54:325-8. 
15. Agency for Toxic Substances and Disease Registry, ATSDR, Toxicological Profile for Lead, US Department of Health and Human Services Public Health Service, 2007.

16. Karita K, Yano E, Dakeishi M, Iwata T, Murata K. Benchmark dose of lead inducing anemia at the workplace. Risk Anal. 2005;25:957-62.

17. Ntzoufras I. Bayesian Modeling Using WinBUGS. Hoboken: Wiley; 2009.

18. Davis JA, Gift JS, Zhao QJ. Introduction to benchmark dose methods and U. S. EPA's benchmark dose software (BMDS) version 2.1.1. Toxicol Appl Pharmacol. 2011;254:181-91.

19. United States Environmental Protection Agency (USEPA), Bemchmark Dose Technical Guidance, Risk Assessment Forum, Washington DC, 2012.

20. Wheeler MW, Bailer AJ. Properties of model-averaged BMDLs: a study of model averaging in dichotomous response risk estimation. Risk Anal. 2007; 27:659-70.

21. Burns CJ, Wright JM, Pierson JB, Bateson TF, Burstyn I, Goldstein DA, Klaunig JE, Luben TJ, Mihlan G, Ritter L, Schnatter AR, Symons JM, Yi KD. Evaluating uncertainty to strengthen epidemiologic data for use in human health risk assessments. Environ Health Perspect. 2014;122:1160-5.

22. Ukaejiofo EO, Thomas N, Ike SO. Haematological assessment of occupational exposure to lead handlers in Enugu urban, Enugu state. Nigeria Niger I Clin Pract. 2009;12:58-64.

23. Pourabdian S, Eizadi-Mood N, Golshiri P, Amini F. The relationship between blood lead level and neuro-psychological and hematological findings in lead-exposed workers of battery industry. Iranian J Toxicol. 2011;5:521-6.

24. Wignall JA, Shapiro AJ, Wright FA, Woodruff TJ, Chiu WA, Guyton KZ, Rusyn I. Standardizing benchmark dose calculations to improve science-based decisions in human health assessments. Environ Health Perspect. 2014;122: 499-505.

25. Holland MG, Cawthon D. Workplace lead exposure. J Occup Env Med. 2016; 58:e371-4.

26. Weisskopf MG, Sparrow D, Hu H, Power MC. Biased exposure-health effect estimates from selection in cohort studies: are environmental studies at particular risk? Environ Health Perspect. 2015:123:1113-22.

27. Chuang HY, Lee ML, Chao KY, Wang JD, Hu H. Relationship of blood lead levels to personal hygiene habits in lead battery workers: Taiwan, 19911997. Am J Ind Med. 1999;35:595-603.

28. Banerjee S, Ramachandran G, Vadali M, Sahmel J. Bayesian hierarchical framework for occupational hygiene decision making. Ann Occup Hyg. 2014;58:1079-93.

29. McNally K, Warren N, Fransman W, Entink RK, Schinkel J, van Tongeren M, Cherrie JW, Kromhout H, Schneider T, Tielemans E. Advanced REACH tool: a Bayesian model for occupational exposure assessment. Ann Occup Hyg. 2014:58:551-65.

30. Flora G, Gupta D, Tiwari A. Toxicity of lead: a review with recent updates. Interdiscip Toxicol. 2012;5:47-58.

31. Cheng Y, Schwartz J, Vokonas PS, Weiss ST, Aro A, Hu H. Electrocardiographic conduction disturbances in association with low level lead exposure. Am J Cardiol. 1998:82:594-9.

32. Payton M, Hu H, Sparrow D, Weiss ST. Low-level lead exposure and renal function in the normative aging study. Am J Epidemiol. 1994;140:821-9.

33. Shaik AP, Jamil K. Individual susceptibility and genotoxicity in workers exposed to hazardous materials like lead. J Hazard Mater. 2009;168:918-24.

34. Grover P, Rekhadevi PV, Danadevi K, Vuyyuri SB, Mahboob M, Rahman MF. Genotoxicity evaluation in workers occupationally exposed to lead. Int J Hyg Environ Health. 2010;213:99-106.

35. Mason LH, Harp JP, Han DY. Pb neurotoxicity: neuropsychological effects of lead toxicity. Biomed Res Int. 2014;840547

36. Chou WC, Chio CP, Liao CM. Assessing airborne PM-bound arsenic exposure risk in semiconductor manufacturing facilities. J Hazard Mater. 2009:167:976-86.

37. Office of Environmental Health Hazard Assessment, OEHHA, Estimating workplace air and worker blood lead concentration using an updated physiologically-based pharmacokinetic (PBPK) model. California Environmental Protection Agency, 2013.

38. Bailer AJ, Wheeler M, Dankovic D, Nobel R, Bena J. Incorporating uncertainty and variability in the assessment of occupational hazards. Int J Risk Assess Manag. 2005;5:344-57.

39. Wheeler MW, Park RM, Bailer AJ, Whittaker C. Historical context and recent advances in exposure-response estimation for deriving occupational exposure limits. J Occup Environ Hyg. 2015;12:S7-17. 